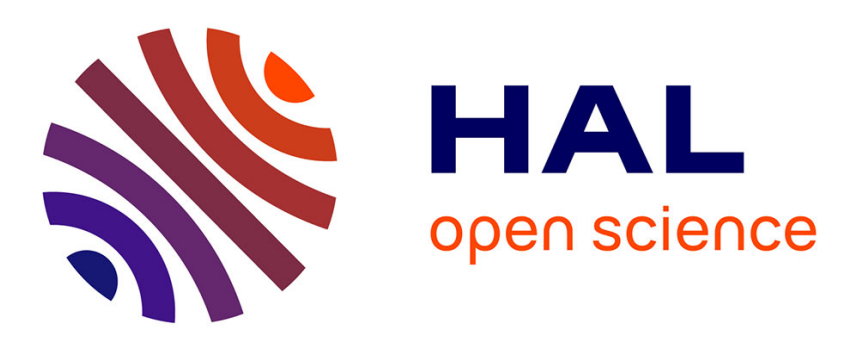

\title{
Alimentation du porc pour la production de viande maigre: évolutions récentes et perspectives
}

\author{
Y. Henry
}

\section{To cite this version:}

Y. Henry. Alimentation du porc pour la production de viande maigre: évolutions récentes et perspectives. Productions Animales, 1993, 6 (1), pp.31-45. hal-00896040

\section{HAL Id: hal-00896040 https://hal.science/hal-00896040}

Submitted on 1 Jan 1993

HAL is a multi-disciplinary open access archive for the deposit and dissemination of scientific research documents, whether they are published or not. The documents may come from teaching and research institutions in France or abroad, or from public or private research centers.
L'archive ouverte pluridisciplinaire HAL, est destinée au dépôt et à la diffusion de documents scientifiques de niveau recherche, publiés ou non, émanant des établissements d'enseignement et de recherche français ou étrangers, des laboratoires publics ou privés. 
INRA Prod. Anim., 1993, 6. (1), $31-45$.

\section{Y. HENRY}

INRA Station de Recherches Porcines $35590 \mathrm{St}$-Gilles

\section{Alimentation du porc pour la production de viande maigre : évolutions récentes et perspectives}

La viande de porc représente une part dominante de la consommation des produits carnés dans la plupart des pays industrialisés. Selon les sources de la FAO (1990), le porc contribuait pour $40 \%$ de la production de viande dans le Monde en 1989, les pourcentages correspondants en Europe, dans la CEE et en France s'élevant respectivement à 51, 45 et $37 \%$. En dehors de cet aspect quantitatif, l'évolution de la consommation de viande de porc au cours des dernières décennies a été caractérisée par une exigence de plus en plus marquée pour des produits maigres, avec le moins possible de gras visible, qu'il s'agisse de la viande fraîche ou des produits transformés. En outre, les qualités diététiques semblent désormais prendre le pas sur les aspects technologiques, en raison notamment de la pression du milieu médical en faveur d'une consommation de graisses animales en quantité moindre et plus insaturées, en opposition avec certaines exigences de la transformation.

\section{Résumé}

La production porcine a bénéficié, au cours des dernières décennies, de progrès importants et continus réalisés par la sélection pour une croissance sans cesse plus forte de tissus maigres et un dépôt décroissant de gras, en réponse à la demande des consommateurs. Cet article examine les changements intervenus dans l'alimentation en considérant les évolutions récentes et les perspectives, compte tenu de l'évolution prévisible des performances de production et de l'apport des nouvelles technologies.

L’importance du progrès génétique en faveur de la croissance des tissus maigres a conduit en premier lieu à envisager une modélisation de la prévision des besoins nutritionnels (énergie, protéines et acides aminés, minéraux), dont les variations se traduisent notamment par des exigences moins marquées en énergie que par le passé et par un accroissement important des besoins en acides aminés relativement à l'apport énergétique.

Grâce à cette démarche de modélisation, il est désormais possible de définir de nouvelles stratégies d'alimentation adaptées pour la production de viande maigre (plan de rationnement alimentaire, choix du type d'aliment pour une phase de production déterminée), en fonction des conditions particulières de production et à l'aide de systèmes d'évaluation des aliments suffisamment discriminants (énergie nette, digestibilité iléale des acides aminés). En outre, l'augmentation de certains intrants alimentaires (azote, phosphore) pour une production accrue de viande maigre implique une gestion raisonnée de leurs apports, afin de prévenir des rejets excessifs dans l'environnement (eau, atmosphère).

La tendance à une certaine dégradation de la qualité de la viande, notamment sous l'angle technologique et organoleptique, au fur et à mesure des progrès de la sélection sur la croissance musculaire, oblige à une prise en compte, par l'alimentation, des exigences de qualité des produits, qu'il s'agisse des dépôts gras ou des tissus maigres (importance du gras intramusculaire). Il en est de même avec le recours à de nouvelles technologies permettant, soit de préserver le potentiel de croissance musculaire (utilisation du porc mâle entier), soit de le stimuler (facteurs de croissance). En dernier lieu, après avoir considéré les effets de l'alimentation sur la conformation des carcasses, en relation avec l'amélioration du développement musculaire, les conséquences d'un amaigrissement excessif des truies sur les performances de reproduction sont évoquées en liaison avec la mobilisation et la reconstitution des réserves lipidiques corporelles. Ce problème d'équilibre entre les tissus musculaire et gras constitue un enjeu important pour l'évolution future de l'alimentation du porc maigre. Au plan de l'application, les nouvelles approches nutritionnelles, basées sur l'établissement de lois de réponse qui prennent en compte la diversité à la fois des types génétiques (depuis les plus gras jusqu'aux plus maigres) et des conditions d'élevage et de milieu devraient permettre, dans chaque cas, de définir les conditions optimales de production d'un type de porc particulier. 
Les professionnels de la filière porcine ont réagi positivement et depuis longtemps à cette évolution de la demande $d u$ consommateur et du marché en développant une production fortement accrue d'une viande de plus en plus maigre, en particulier grâce aux efforts continus de la sélection. Ainsi, en France, au cours des 30 dernières années (Leclercq et Legault 1991), le progrès génétique pour le gain moyen journalier pendant l'engraissement a été de $250 \mathrm{~g}$, parallèlement à une augmentation du taux de muscle dans la carcasse de l'ordre de 10 points. L'amélioration de la croissance, et principalement de la fraction musculaire, s'est accompagnée d'une diminution du coût alimentaire de $0,18 \mathrm{~kg}$ d'aliment par $\mathrm{kg}$ de gain de poids vif. Cette évolution, jusqu'à présent quasi-linéaire, des performances de croissance est appelée à se poursuivre, quoique probablement à un rythme un peu ralenti, compte tenu du risque de détérioration de la qualité de la viande avec l'augmentation de l'intensité de croissance musculaire. Dans les dix prochaines années, selon les mêmes auteurs, on peut s'attendre à un progrès génétique supplémentaire de $100 \mathrm{~g}$ de gain journalier, de 5 points de taux de muscle, et 0,10 à 0,20 d'indice de consommation en moins. En ce qui concerne la reproduction, la productivité numérique des truies n'a également cessé de progresser, ce qui contribue à une diminution progressive de la part des frais fixes d'alimentation par porc produit. En 20 ans, en France (Dagorn et al 1992), le nombre de porcelets sevrés par truie et par an a augmenté de 6 unités, correspondant à une accélération du rythme de reproduction : la durée de la lactation a ainsi diminué de 30 jours pour se stabiliser aux alentours de 28 jours, tandis que l'intervalle sevrage-fécondation s'est abaissé de 21 à 15 jours. Pour les prochaines années, le progrès supplémentaire au niveau de la productivité numérique résultera principalement d'une réduction encore plus importante de l'intervalle sevragefécondation, et d'une amélioration du taux de survie des porcelets à la naissance, parallèlement à la sélection de lignées de truies à plus forte prolificité (taille de la portée à la naissance).

Cette progression soutenue vers une production accrue de viande maigre s'est traduite, au niveau de l'alimentation, par des changements importants pour apporter les adaptations nécessaires à l'optimisation des performances de croissance. Ceci nous conduit à envisager les changements récents dans ce domaine, ainsi que les perspectives qui en découlent, compte tenu de l'évolution prévisible des performances de production et de l'apport des nouvelles technologies au cours des prochaines années. Pour cela, nous considérerons dans un premier temps les nouvelles approches pour l'estimation des besoins nutritionnels du porc, basées sur une démarche de modélisation, prenant en compte la diversité des facteurs impliqués et la complexité croissante de leurs interrelations. Nous examine-

Rapport présenté à la Semaine Scientilique de la France en Ukraine ("Oukraina 92"), Journée Agro-alimentaire INRA, Kiev, 8 Juin 1992 rons ensuite les stratégies d'alimentation adaptées pour la production de viande maigre, avant d'aborder les moyens permettant, par l'alimentation, de mieux prendre en compte les contraintes de qualité des produits.

\section{1 / Mieux prévoir les besoins nutritionnels}

Les progrès de la sélection dans l'espèce porcine ont entraîné un fort accroissement de la variabilité génétique, à la fois intra-race et entre races ou lignées, notamment grâce au développement de lignées synthétiques spécialisées pour la production de viande maigre. Ainsi, si l'on considère les génotypes extrêmes (Noblet et al 1991), le rapport muscle / gras peut varier de moins de $1 \mathrm{chez}$ les animaux les plus gras (porcs de races traditionnelles ou chinoises) à plus de 4 chez les porcs les plus maigres (lignées mâles pour les croisements terminaux), tandis que la vitesse de croissance moyenne est multipliée par 2 ou par 3 . Cette extrême variabilité du niveau des performances selon les types de porc et les pays, jointe à la diversité des conditions de production et de climat, conduit à la nécessité d'envisager une prévision des variations des besoins nutritionnels (énergie, protéines et acides aminés, minéraux) en fonction du potentiel de production. Ce dernier s'exprime principalement par l'intensité de la croissance musculaire relativement au dépôt gras, qui détermine la répartition de l'énergie fixée dans les tissus entre les protéines et les lipides. On ne peut plus ainsi se contenter, pour l'alimentation des porcs, de recommandations moyennes, telles qu'elles ont été pratiquées jusqu'à présent. Dès lors, au cours des dernières années on a vu se développer une nouvelle démarche de prévision factorielle des besoins, basée sur une quantification des dépenses (entretien, production) et des rendements d'utilisation des nutriments pour la formation des dépôts corporels, en prenant en compte la diversité des facteurs impliqués et leur contribution variable au niveau de la production.

\section{1 / Des porcs maigres moins exigeants en énergie}

Un certain nombre de travaux ont été consacrés récemment à l'estimation des composantes du besoin énergétique du porc en croissance, à partir des données de bilans énergétiques en chambre respiratoire et de résultats d'analyse chimique corporelle par la technique des abattages. Sur l'ensemble de la phase de croissance, selon Noblet et al (1989b, 1991), l'évolution de la dépense énergétique d'entretien, exprimée en énergie métabolisable (EM), fait apparaître une relation étroite de proportionnalité avec le poids vif élevé à la puissance 0,60 , meilleure qu'avec l'exposant habituel $0,75\left(1050 \mathrm{~kJ} \mathrm{EM} / \mathrm{kg}^{0,60}\right)$. Cette estimation du besoin d'entretien, qui varie d'ailleurs selon l'origine génétique (en relation probablement avec la contribution importante des viscères, foie et tube digestif, à la production de cha- 
leur), a permis de mieux préciser les rendements d'utilisation de l'EM pour la formation des dépôts de lipides (kf) et surtout de protéines (kp). Ces rendements, en effet, étaient sous-estimés du fait de la sous-estimation de la dépense d'entretien avec le coefficient 0,75 . Le rendement $\mathrm{kf}$ pour le dépôt de lipides est plus élevé que le rendement kp pour le dépôt de protéines, soit respectivement 0,80 et 0,64 , correspondant à un rendement moyen d'utilisation de l'EM pour la croissance de 0,75 . L'amélioration du potentiel de croissance musculaire par la sélection s'accompagne ainsi d'une diminution inéluctable du rendement global de l'utilisation de l'énergie alimentaire pour la croissance, les animaux étant d'autant moins efficients dans cette utilisation qu'ils sont plus maigres.

Alors qu'antérieurement, avec une production relativement importante de gras, l'apport énergétique, et donc l'ingestion alimentaire ou l'appétit, était principalement en relation avec le dépôt gras, chez les porcs modernes de type maigre l'apport énergétique devient davantage en relation avec le dépôt de protéines. Les travaux récents (Noblet et al 1991, Karege 1991) ont montré en effet que les protéines fixées contribuent pour la plus grande part au gain pondéral : un dépôt d'1 g de protéines dans l'organisme s'accompagne d'une fixation de 3 à $4 \mathrm{~g}$ d'eau, correspondant à un gain pondéral de $4,4 \mathrm{~g}$, tandis qu'un dépôt d'1 $\mathrm{g}$ de lipides est associé à un gain pondéral équivalent (1 g). Compte tenu des contenus respectifs en énergie des tissus maigres (dont les muscles, renfermant la plus grande partie des protéines) et des dépôts gras (constitués essentiellement de lipides), et des différences de rendement d'utilisation de l'énergie alimentaire (EM) pour la formation des dépôts de protéines et de lipides, on en déduit que le coût énergétique de la formation du gras est de 3 à 3,5 fois supérieur à celui de la formation des tissus maigres : respectivement 10, 12 et $40 \mathrm{~kJ}$ d'EM /g pour le muscle, les tissus maigres et les dépôts gras. De plus, il ressort des coûts de formation d'1 $\mathrm{g}$ de protéines et de lipides, soit respectivement 40 et $50 \mathrm{~kJ}$ d'EM, que le coût d'EM par g de gain pondéral associé au dépôt de protéines est de $9 \mathrm{~kJ}$ seulement contre $50 \mathrm{~kJ}$ ( 5,5 fois plus) pour celui associé au dépôt de lipides. En d'autres termes, à vitesse de croissance constante, l'augmentation de la teneur en muscle du gain pondéral nécessite un apport d'énergie alimentaire moindre, accompagné d'une diminution corrélative de l'indice de consommation, ce qui a pu être interprété comme une baisse de l'appétit chez les porcs de type maigre comparativement aux porcs de type gras. Avec la sélection en faveur d'une vitesse de croissance et d'une teneur en muscle simultanément accrues, le besoin énergétique et la consommation d'aliment augmentent beaucoup moins fortement que dans le cas des animaux gras. L'efficacité alimentaire est donc d'autant meilleure que les animaux sont plus maigres et ont une croissance plus rapide, en dépit d' une efficacité moindre de fixation de l'énergie alimentaire dans les dépôts corporels.

Sur le plan de l'application, des modèles de
Figure 1. Variations du coût énergétique du gain pondéral entre 20 et $95 \mathrm{~kg}$ de poids vif, en fonction du rapport muscle/gras dans la carcasse à l'abattage (d'après Noblet et al 1991 et non publié).

Coût énergétique ( $M J$ d'EM $/ \mathrm{kg}$ )

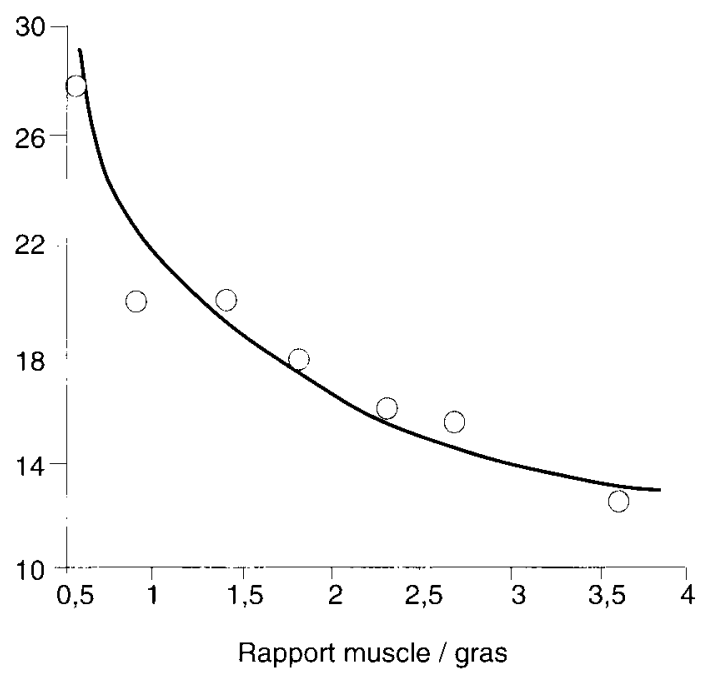

prévision de la croissance pondérale et du besoin énergétique ont été élaborés dans un premier temps à partir des courbes d'évolution avec l'âge (ou le poids vif) des dépôts journaliers de protéines et de lipides (Whittemore 1983, Black et al 1986), mais ils restent relativement théoriques, puisqu'ils ne permettent pas de prendre directement en compte les performances de production réellement quantifiables dans l'élevage (gain journalier, caractéristiques des carcasses à l'abattage). C'est précisément dans cette voie qu'évoluent certains modèles de prévision en cours d'élaboration (J. Noblet et al non publié), qui permettent de faire la liaison complète entre les intrants alimentaires, les dépôts de constituants chimiques et tissulaires, et enfin les performances de production. D'ores et déjà, on peut penser que le rapport muscle / gras, en tant que paramètre indicateur de la composition tissulaire du gain de poids vif, constitue un bon prédicteur du coût énergétique du gain, composante essentielle du besoin énergétique du porc en croissance (figure 1, d'après Noblet et al 1991, et non publié). Chez la truie reproductrice, en gestation et en lactation, la détermination du besoin énergétique par la méthode factorielle est désormais opérationnelle (Noblet et al 1988, 1990). Sa mise en oeuvre dans la pratique de l'élevage s'appuie sur l'enregistrement des performances de reproduction (taille et croissance de la portée, variations pondérales, état corporel) et permet une conduite alimentaire individualisée par truie en fonction de son niveau de production.

\section{2 / Des besoins sans cesse accrus en protéines et en acides aminés}

La prévision factorielle du besoin azoté est moins facile à appréhender que celle du besoin énergétique, en raison en particulier d'une certaine imprécision dans la définition et la quantification des dépenses azotées (protéines,
A même vitesse de croissance, le coût énergétique du gain de poids est plus faible chez les porcs maigres que chez les porcs gras. 
Figure 2. Prévision de la rétention azotée $(g / j)$ chez le porc en croissance entre 25 et $100 \mathrm{~kg}$ de poids vif, en fonction du gain journalier de poids vif et du pourcentage de muscle dans la carcasse à l'abattage (Dourmad et al 1992).

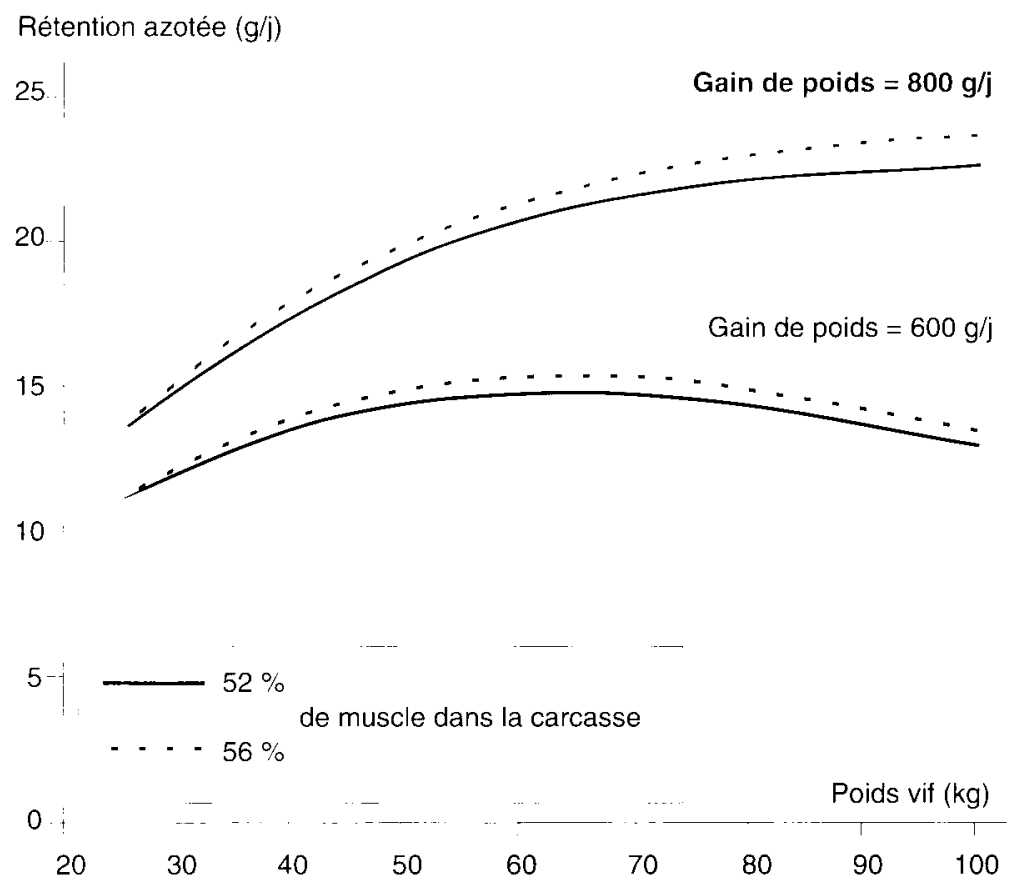

Figure 3. Représentation schématique de la relation enttre l'acide aminé limitant et l'excès de protéines dans le régime.

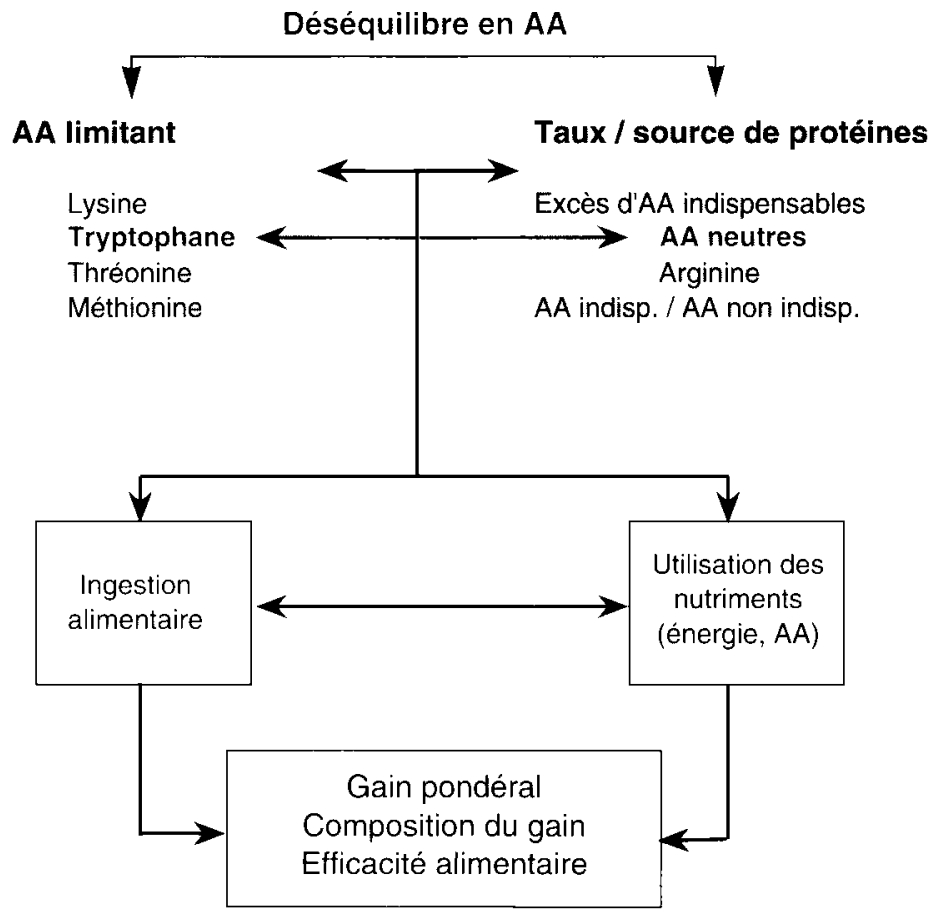

Les proteimes en excès (acides aminés indispensables ou non indispensables) peuvent interagir avec l'acide aminé limitant, en affectant l'ingestion alimentaire et/ou l'utilisation métabolique des acides aminés, et donc les performances de croissance. C'est le cas des acides aminés vis-à-vis du tryptophane.

Acides aminés neutres = Leucine + Isoleucine + Valine + Phénylalanine + Tyrosine . acides aminés) d'origine endogène pour l'entretien. Suivant le concept développé par Fuller (1991), des modèles de prévision, basés sur les variations des dépôts de protéines et d'acides aminés au cours de la croissance, ont reçu un début d'application (Whittemore 1983, Black et al 1986, Moughan et al 1987, Moughan 1989), mais, comme pour le besoin énergétique, ils ne sont pas adaptés pour une correction en fonction des critères mesurés dans l'élevage. Quoi qu'il en soit, les observations récentes (Henry 1988 , Sève et Ballèvre 1991) ont montré que le besoin azoté, qu'il s'agisse des acides aminés indispensables ou de l'azote indifférencié, est surtout en relation avec l'importance du dépôt de protéines corporelles, dont la composition en acides aminés est relativement constante tout au long de l'engraissement. En outre, le dépôt de protéines lui-même est essentiellement fonction de la vitesse de croissance, compte tenu des variations relativement faibles de la teneur en protéines du gain pondéral dans les lignées de porcs de type maigre: de l'ordre de $16 \%$ de protéines dans le gain de poids vif vide entre 20 et $100 \mathrm{~kg}$ de poids vif, selon Noblet et al (1991). Ceci explique que dans la prévision de la courbe de rétention azotée avec l'âge ou le poids vif la contribution du gain journalier est prédominante par rapport au taux de muscle dans la carcasse à l'abattage (Dourmad et al 1992, figure 2). Cette démarche de prévision factorielle des besoins en acides aminés, en considérant le cas particulier de la lysine, a pu être plus aisément mise en application chez la truie en lactation, en raison de la relative facilité de quantifier les exportations d'acides aminés dans le lait (Dourmad et al 1991).

La prévision du besoin azoté en fonction du potentiel de production de viande maigre a été grandement simplifiée grâce au développement du concept de besoin en protéine équilibrée ou "idéale" (Fuller 1991), sur la base de rapports constants entre les besoins en acides aminés indispensables : la lysine est prise comme référence en raison de son caractère généralement limitant dans le régime alimentaire du porc en croissance. Les travaux récents (Henry et al 1988a) ont ainsi abouti à la formulation d'apports recommandés d'acides aminés pour la croissance, sous la forme de rapports définis entre les acides aminés indispensables et la lysine, correspondant au profil de composition de la protéine idéale en acides aminés (tableau 1). Il suffit alors de connaître les variations du besoin en lysine selon le type de porc et son potentiel de croissance pour en déduire les besoins pour les autres acides aminés. On peut retenir que sur la base de $15 \%$ de protéines dans le gain de poids vif (d'après Noblet et al 1991) et $7 \%$ de lysine dans les protéines fixées, le besoin de lysine parfaitement disponible par kg de croît s'établit, pour un rendement de fixation de 0,70 (Henry et al 1988), aux alentours de $15 \mathrm{~g}$, soit environ $18 \mathrm{~g} / \mathrm{kg}$ de gain pour une digestibilité iléale de la lysine de 0,85 . Par ailleurs, si l'on considère que la lysine représente 6,5 à $6,8 \%$ de la protéine idéale (Fuller 1991), le taux minimum de protéines totales (sommes des acides ami- 
nés indispensables et non indispensables sensiblement équivalentes) devrait correspondre à environ 15 fois le besoin en lysine.

En réalité, le concept strict de protéine idéale n'est pas applicable aux conditions habituelles d'alimentation, caractérisées par des relations de déséquilibre parmi les acides aminés, qu'il s'agisse de certains acides aminés indispensables entre eux ou de l'acide aminé limitant par rapport à l'ensemble des protéines. Les conséquences d'un tel déséquilibre se manifestent surtout par un effet dépressif sur l'ingestion alimentaire, et par contre coup sur les performances de croissance. Les travaux réalisés dans notre laboratoire (Henry et Sève 1991, Henry et al 1992a,b) ont permis précisément de mettre en évidence la spécificité et le rôle physiologique particulier de certains acides aminés indispensables dans ces relations d'équilibre (figure 3). A la différence de la lysine, l'apport d'un excès de protéines par rapport au tryptophane, lorsque ce dernier est limitant, entraîne une forte dépression de la consommation d'aliment et de la croissance. Cet effet s'explique par un antagonisme entre le tryptophane et les autres acides aminés neutres de grande taille (acides aminés ramifiés et aromatiques) lors de leur passage à travers la barrière hémato-encéphalique, provoquant une diminution de la synthèse de sérotonine cérébrale, qui constitue l'un des neuromédiateurs clés dans la régulation centrale de la prise alimentaire. Ces résultats confirment l'effet stimulant de l'amélioration de l'équilibre en acides aminés sur l'appétit, et à l'inverse l'auto-limitation de la consommation d'aliment à la suite d'une surcharge du régime en protéines, comme l'ont montré les travaux antérieurs (Henry 1988). Par ailleurs, il semble que les animaux de type maigre soient particulièrement sensibles aux problèmes de déséquilibre en acides aminés : c'est le cas, par exemple, des porcs femelles comparativement aux mâles castrés, en réponse à un excès de protéines par rapport au tryptophane (Henry et al 1992b). On peut penser que la formulation de régimes mieux équilibrés en acides aminés, donc à teneur abaissée en protéines,

Tableau 1. Rapports recommandés entre les besoins en acides aminés indispensables chez le porc en croissance (par référence à la lysine : 1,00) (Henry et al 1988, INRA 1989)

\begin{tabular}{|c|c|}
\hline Lysine & 1,00 \\
\hline Méthionine + cystine & 0,60 \\
\hline Méthionine $^{\mathrm{a}}$ & 0,30 \\
\hline Thréonine & 0,65 \\
\hline Tryptophane & 0,18 \\
\hline Isoleucine & 0,60 \\
\hline Leucine & 0,72 \\
\hline Valine & 0,70 \\
\hline Phénylalanine + Tyrosine ${ }^{\mathrm{b}}$ & 1,00 \\
\hline Histidine & 0,26 \\
\hline Arginine & 0,45 \\
\hline
\end{tabular}

${ }^{\text {a }}$ Sur la base d'au moins $50 \%$ de méthionine dans l'apport total d'acides aminés soufrés.

${ }^{\mathrm{b}}$ La tyrosine peut contribuer pour $50 \%$ du besoin total en acides aminés aromatiques. grâce à l'apport supplémentaire d'acides aminés limitants sous forme libre, constitue un moyen efficace pour stimuler l'appétit limité des porcs de type maigre et à croissance rapide.

En définitive, le besoin énergétique du porc en croissance est essentiellement fonction de l'intensité de la croissance et de la composition tissulaire du gain de poids (rapport muscle / gras), tandis que les besoins en acides aminés (en apports journaliers) sont étroitement associés au gain pondéral et aux protéines qui y sont déposées. L'accentuation des efforts de la sélection en faveur d'une production accrue de viande maigre se traduit par un taux d'accroissement des besoins journaliers de protéines et d'acides aminés plus important que celui du besoin énergétique, et de l'ingestion alimentaire. Ceci a pour conséquence une forte augmentation des besoins relatifs de protéines et d'acides aminés par rapport à l'énergie (rapport protéines-énergie), ce qui n'est pas sans incidence sur la formulation des aliments et l'approvisionnement en matières premières (part accrue des sources azotées riches).

En ce qui concerne les minéraux, et notamment les macroéléments (calcium, phosphore), la prévision des besoins par la méthode factorielle y a trouvé sa première application, en raison de la relative simplicité du modèle comparativement à l'énergie et aux acides aminés (Guéguen et Perez 1981, Jongbloed 1987).

\section{2 / Nouvelles stratégies d'alimentation}

L'adéquation optimale des apports alimentaires aux besoins du porc pour la production de viande maigre implique en premier lieu une bonne base d'évaluation nutritive des aliments, qu'il s'agisse de l'énergie ou des acides aminés (Henry et al 1988a). Il convient ensuite, au niveau du rationnement alimentaire, de définir les apports de nutriments (énergie, protéines et acides aminés) en fonction des potentialités des animaux, ainsi que des objectifs de production et des conditions de milieu. La prise en compte des contraintes de l'environnement (réduction des rejets) apporte une dimension nouvelle dans la valorisation des intrants alimentaires pour une production intensive de viande maigre.

\section{1 / Des systèmes d'évaluation nutritive des aliments plus discriminants}

\section{a / Une préférence pour une évaluation sur la base de l'énergie nette}

Les travaux réalisés récemment au laboratoire ont conduit à l'élaboration d'un nouveau système d'énergie nette (EN) pour l'évaluation des aliments et des matières premières, dans le contexte d'utilisation d'animaux de type maigre et à croissance rapide (Noblet et al $1989 \mathrm{a}$, Noblet et al 1990, Noblet et Henry
Le besoin azoté dépend surtout de l'importance du dépôt de protéines corporelles. L'accentuation de la sélection vers la production de viande maigre se traduit par un accroissement du besoin en protéines alimentaires. 
Tableau 2. Hiérarchie des valeurs énergétiques de quelques matières premières pour le porc, selon le système d'évaluation (Noblet et al 1989, 1990).

\begin{tabular}{|lcc|}
\hline & \multicolumn{2}{c|}{ Système énergétique } \\
Matière première & ED & EN \\
\hline Maïs (MJ/kg MS) & 15,79 & 12,41 \\
\% Maïs & 100 & 100 \\
Orge & 95 & 93 \\
Blé & 102 & 98 \\
Tourteau soja & 103 & 65 \\
Pois & 103 & 89 \\
Manioc & 100 & 104 \\
Gluten feed maïs & 55 & 52 \\
Graisses & 189 & 236 \\
\hline
\end{tabular}

ED : Energie digestible, EN : Energie nette

1991). Par rapport aux systèmes d'énergie nette existants (dont le système NEF de Rostock, selon Schiemann et al 1972), les résultats obtenus confirment, comme pour les animaux de type gras (système NEF), le faible rendement d'utilisation de l'énergie des protéines comme substrat métabolisable $(0,54)$. Par contre, les lipides et l'amidon constituent des substrats particulièrement efficaces pour la conversion en EN (rendements respectifs de 0,94 et 0,85 ), tandis que l'énergie provenant de la dégradation des parois végétales est utilisée avec un rendement faible $(0,56$ pour les parois totales ou fraction NDF), voire nul dans le cas de la cellulose brute. Un ensemble d'équations de prédiction sont proposées, permettant d'estimer l'EN, soit à partir des éléments digestibles (ou métabolisables) fournis par les tables, soit à partir d'une combinaison de prédicteurs associant l'énergie digestible (ED) ou l'EM et certaines caractéristiques de composition chimique de l'aliment, parmi lesquelles les teneurs en protéines, lipides, amidon et parois végétales. En particulier, les valeurs d'ED des tables (INRA 1989) sont aisément convertibles en valeurs EN, après prise en compte de la répartition qualitative des différents nutriments (protéines, lipides, amidon et fibres). Les données ainsi obtenues montrent que, comparativement à l'ED (tableau 2), le système EN est en faveur de régimes à teneur plus faible en protéines et mieux équilibrés en acides aminés, en même temps mieux pourvus en amidon et renfermant moins de parois végétales. Réciproquement, l'énergie nette confirme son intérêt avec l'utilisation prédominante de régimes à teneur élevée en protéines relativement à l'énergie, comme c'est le cas pour les animaux à haut niveau de performances, et à forte incorporation de produits de substitution des céréales souvent chargés en fibres.

\section{b / Evaluation des protéines et des acides aminés sur la base de la digestibilité iléale}

Le développement de la production porcine en Europe Occidentale s'est traduit par une forte augmentation de la consommation des produits de substitution des céréales, dont l'intérêt économique a souvent pour contrepartie une digestibilité moindre des protéines et des acides aminés, en raison de leur teneur souvent élevée en parois végétales (Henry et al 1988b). Les nouvelles connaissances sur l'utilisation digestive des acides aminés chez le porc (Laplace et al 1985, Rérat 1991) permettent désormais de raisonner les besoins et les apports d'acides aminés sur la base de leur digestibilité iléale (à la fin de l'intestin grêle) et, par voie de conséquence, de mieux ajuster les apports alimentaires aux besoins, comparativement à une situation de pléthore avec une marge de sécurité trop importante. Des tables de valeur de digestibilité iléale des acides aminés dans les matières premières, selon leurs caractéristiques particulières (origine botanique, composition, traitements technologiques) sont ainsi disponibles pour la formulation des aliments (Eurolysine 1988, RPAN, 1989, CVB 1990). Au delà de ces valeurs moyennes par type de matière première, des équations de prédiction viennent d'être établies (Mariscal-Landin 1992), qui permettent des corrections en fonction d'indicateurs spécifiques pour tenir compte notamment de l'origine botanique ou des traitements technologiques (teneurs en parois végétales dans les issues de meunerie, teneur en tannins du sorgho, facteurs antitrypsiques du pois, par exemple). D'après les résultats préliminaires (Mariscal-Landin et al 1991), les méthodes in vitro semblent présenter des perspectives intéressantes pour une exploration systématique de la variabilité de la disponibilité digestive des acides aminés dans des matières premières de plus en plus diversifiées.

\section{2 / Un rationnement alimentaire adapté pour la production d'un porc maigre}

Jusqu'à présent, avec les génotypes conventionnels présentant une propension à déposer une quantité importante de gras dans les conditions d'alimentation à volonté, il a été d'usage de pratiquer une restriction alimentaire afin de limiter l'état d'engraissement à l'abattage et obtenir ainsi des carcasses répondant mieux aux besoins de la commercialisation. Cette intensité de la restriction alimentaire, qui se situe à un certain niveau en dessous de la capacité d'ingestion à volonté (généralement 5 à $20 \%$ ) est alors d'autant plus sévère que les porcs sont plus gras. Elle est plus importante pour les mâles castrés (de l'ordre de $20 \%$ ) que pour les femelles ( 5 à $10 \%$ ), qui sont plus maigres. Il en est de même pour les génotypes gras (environ $50 \%$ de muscle dans la carcasse) comparativement aux génotypes maigres (aux alentours de $60 \%$ de muscle). L'indice de consommation est peu modifié, plutôt légèrement amélioré, par rapport à l'alimentation à volonté, en raison d'effets opposés résultant de la réduction du coût énergétique du gain de poids vif et de l'augmentation de la dépense d'entretien (allongement de la durée d'engraissement). 
L'objectif du rationnement alimentaire en vue de l'amélioration de la qualité des carcasses est en fait d'optimiser à la fois le gain moyen journalier, la teneur en muscle de la carcasse et l'efficacité alimentaire, en minimisant le dépôt de gras. Pour cela, il convient, pour un type de porc donné, de définir les apports d'énergie et d'acides aminés permettant d'obtenir un dépôt journalier maximum de protéines, qui assure le gain pondéral le plus important (plus de 4 fois le dépôt de protéines, contre à peine l'équivalent pour le dépôt de lipides), et par là même le coût alimentaire minimal du gain. Les études de rationnement alimentaire doivent ainsi être reconsidérées en prenant en compte le contexte local particulier de la production, qui intègre le type génétique, les caractéristiques de carcasse à produire et le milieu climatique. Les données de Campbell (1988) ont montré que les génotypes de porcs à fort développement musculaire et à croissance rapide répondent à l'accroissement de l'apport énergétique jusqu'au niveau à volonté, les apports d'acides aminés étant assurés par ailleurs, en déposant une quantité croissante de protéines, alors que la teneur en gras du gain de poids vif atteint un plateau. Cette réponse contraste avec celle de type linéaire-en plateau observée chez les animaux de type gras, indiquant que l'élévation de l'apport énergétique au delà du niveau correspondant au potentiel de dépôt de protéines, entraîne alors inévitablement une accentuation de l'état d'engraissement. Cela signifie aussi que l'appétit limité des lignées de porcs à haut niveau de performances et de type maigre justifie dans ce cas une conduite alimentaire à volonté, ou tout au moins très proche du niveau à volonté. Il n'en reste pas moins que pour ce type de porc à forte croissance musculaire la castration chez le mâle maintient sa propension à accentuer l'état d'engraissement, d'une facon d'ailleurs variable selon le type génétique et sa précocité de développement (Desmoulin et Bonneau 1979)

En dehors de l'aspect génétique, la température ambiante constitue un élément essentiel dans la valorisation des aliments par le porc pour la production de viande maigre, en raison de l'importance de la thermorégulation dans les dépenses énergétiques totales. Les travaux de Le Dividich et Rinaldo (1989), Rinaldo et Le Dividich (1991), confirment que le coût alimentaire chez le porc dépend étroitement de la température moyenne du local d'élevage et de ses fluctuations au cours du nycthémère. Dans les conditions d'élevage sur caillebotis, telles qu'elles sont généralement pratiquées, ils concluent, pour le porc en croissance, à l'intérêt du maintien dans les bâtiments d'une température ambiante relativement élevée (24$25^{\circ} \mathrm{C}$ ), proche de la thermoneutralité, pour obtenir un coût alimentaire minimum. C'est ainsi qu'une augmentation de la température de $1{ }^{\circ} \mathrm{C}$ entre 20 et $25^{\circ} \mathrm{C}$ entraine une économie de 1,2 à $1,4 \mathrm{~kg}$ d'aliment par porc produit. Bien entendu, l'obtention d'une telle température optimale pour la valorisation maximale de l'aliment implique une bonne isolation ther- mique associée à un renouvellement de l'air adéquat, en vue de la conservation de la chaleur produite par les animaux dans le bâtiment. Pour définir ce taux minimum de renouvellement de l'air dans les porcheries, il y a lieu de quantifier les effets des constituants de l'air, et notamment de l'hygrométrie et de certains gaz nocifs comme l'ammoniac, sur les performances de production et la santé des animaux, comme de l'éleveur. Notons par ailleurs que les conditions optimales d'ambiance (température, hygrométrie, renouvellement de l'air) mériteraient d'être reconsidérées dans le cas des porcs de type maigre, compte tenu de leur appétit plus faible et d'une isolation thermique affaiblie par une couverture graisseuse en constante diminution.

\section{3 / Une alimentation plus respectueuse des contraintes de l'environnement}

L'intensification de la production porcine dans les pays industrialisés a conduit à une accélération du mouvement de concentration des élevages dans des régions spécialisées, bénéficiant d'un environnement structurel (industries d'amont et d'aval) favorable. Cette évolution s'est accompagnée d'une montée en puissance des préoccupations liées à la protection de l'environnement, face à l'augmentation des rejets dans le milieu naturel (pollution des eaux par les nitrates et le phosphore, émissions d'ammoniac dans l'atmosphère), à la suite de la généralisation de l'élevage des porcs sur caillebotis avec production de lisier (Aumaitre 1991). Actuellement, le porc excrète environ les $2 / 3$ de l'azote qu'il ingère, et 70 à $80 \%$ du phosphore consommé. C'est dire qu'une marge de progrès importante existe, afin de proposer des solutions préventives permettant, par l'alimentation, de réduire les rejets d'azote et de phosphore dans les lisiers et l'atmosphère, tout en maintenant les performances de production à leur niveau optimum, et ceci avant d'envisager des moyens coûteux de traitement des lisiers excédentaires.

La pollution azotée de l'environnement par les excès de protéines dans l'alimentation du porc a fait l'objet d'un certain nombre de mises au point, parmi lesquelles les revues de Lenis (1989), Tamminga et Verstegen (1991), Dourmad et Guillou (1991), Henry (1991), Jongbloed et Lenis (1992), Henry et Dourmad (1992). Les travaux en cours visent à examiner les possibilités d'ajustement, par les techniques de modélisation, des apports de protéines et d'acides aminés, en quantités digestibles au niveau iléal, en fonction du potentiel de croissance, et de prévoir ainsi les rejets d'azote dans des conditions de production et de productivité définies à l'échelle de l'élevage ou de la région (Dourmad et al 1992). Une deuxième voie de recherche consiste à réduire les intrants azotés quantitatifs grâce à l'amélioration de l'équilibre du régime en acides aminés, notamment par la supplémentation à l'aide des acides aminés industriels. La mise au point de nouvelles stratégies d'alimentation (aliments équilibrés à teneur modérée en protéines, ali-
Réduire la teneur en protéines du régime grâce à l'amélioration de l'équilibre entre acides aminés permet de diminuer les rejets azotés. 
L'équilibre alimentaire et les conditions de milieu agissent non seulement sur la composition tissulaire mais aussi sur la conformation des carcasses.

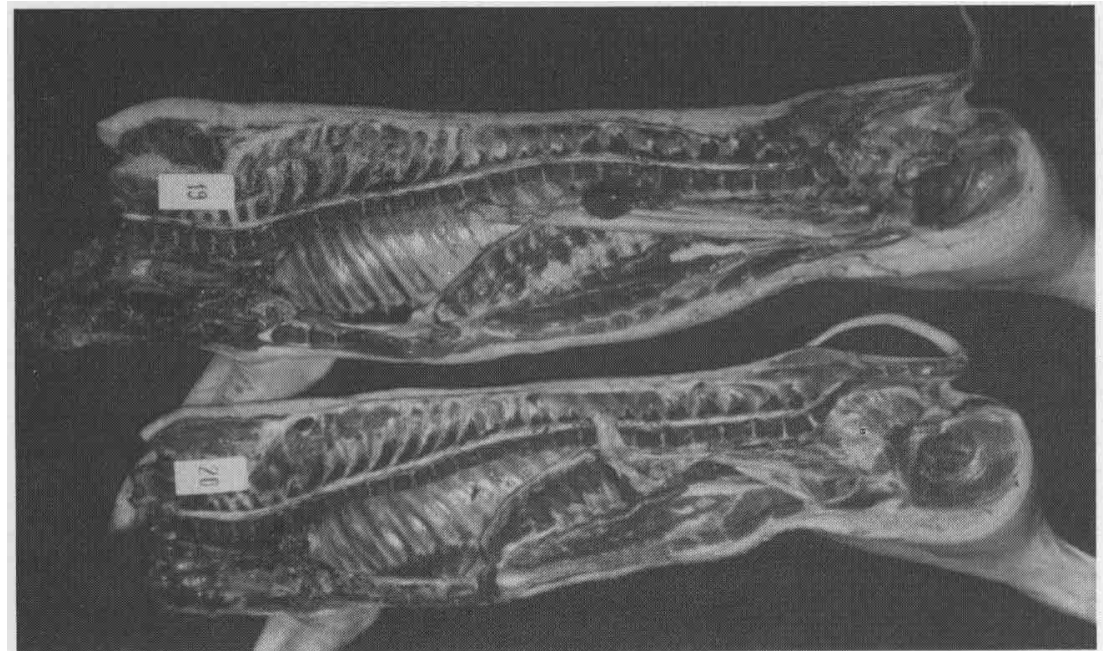

mentation par phase procurant une excrétion azotée minimale) devrait conduire à une réduction des rejets d'azote de l'ordre de 30 à $40 \%$ par rapport à la situation de pléthore actuelle. Certaines observations (Pessara et Oldenburg 1992) semblent indiquer qu'une réduction quantitative de la teneur en protéines du régime, accompagnée d'un rééquilibrage des teneurs en acides aminés, contribue à diminuer non seulement l'excrétion d'azote dans les déjections (urine) mais aussi le dégagement d'ammoniac dans la porcherie et le milieu environnant. Il reste aussi à évaluer l'impact d'une telle gestion raisonnée de l'alimentation azotée au plan économique (coût de production, coûts comparatifs des mesures préventives et du traitement des rejets, qualité de l'eau). Cela devrait permettre de fixer la limite acceptable pour la réduction des rejets d'azote dans des conditions économiques et d'environnement déterminées.

Il est important de noter que la mise en oeuvre d'une alimentation azotée respectueuse de l'environnement va de pair avec les orientations visées pour améliorer l'efficacité de la production de porc maigre. Il suffit de rappeler qu'un régime bien équilibré en acides aminés permet d'améliorer l'utilisation nette de l'énergie pour la croissance en abaissant la production d'extra-chaleur résultant du catabolisme des acides aminés en excès (Noblet et al 1987) et, selon toute vraisemblance, de stimuler l'appétit limité des génotypes maigres à croissance rapide (Henry 1988). De la même façon, une gestion raisonnée de l'alimentation azotée pour un rejet d'azote minimum conduit à privilégier les systèmes d'évaluation des aliments basés sur l'énergie nette et les acides aminés digestibles au niveau iléal. Cette problématique devrait être en faveur de l'utilisation de nutriments à forte bio-disponibilité, comme l'amidon et les acides aminés hautement digestibles. Ces derniers doivent d'ailleurs être fournis en quantités de plus en plus importantes par rapport à l'énergie, au fur et à mesure du progrès génétique pour une production toujours accrue d'une viande de plus en plus maigre.
En ce qui concerne le phosphore, l'usage de bonnes pratiques alimentaires aboutit de la même façon à réduire les rejets dans les lisiers et le lessivage dans les eaux après épandage. Comme l'ont montré les travaux néerlandais (Jongbloed et al 1991, Jongbloed et Lenis 1992, Beers et Jongbloed 1992), ainsi que Pointillart et al (1993), la formulation des aliments sur la base du phosphore digestible, la prise en compte de l'activité phytasique naturelle de certaines matières premières et la supplémentation du régime à l'aide d'une phytase bactérienne conduisent à un meilleur ajustement des apports aux besoins et à une meilleure utilisation $\mathrm{du}$ phosphore phytique, autorisant par là même une réduction des taux d'incorporation de phosphore total et des rejets, qu'on peut estimer à environ $40 \%$.

\section{3 / Prendre en compte la qualité de la viande}

En nous référant à la carcasse comme matière première dont les caractéristiques doivent répondre aux besoins du marché et de la consommation, la première exigence de qualité apparaît d'abord dans une faible teneur en gras, et principalement dans la partie visible du produit (gras externe et intermusculaire). Il convient en outre de prendre en considération la qualité du gras lui-même, à travers sa composition en acides gras, largement influencée par l'alimentation mais aussi sous la dépendance des facteurs génétiques. Un deuxième aspect a trait à la qualité du muscle, qui risque d'être influencée par la poursuite d'une production de plus en plus intensive de viande maigre.

\section{1 / Alimentation et qualité du gras}

Parallèlement à la diminution quantitative des dépôts gras, la sélection sur la croissance des tissus maigres se traduit par un dépôt de graisses plus riches en acides gras insaturés que par le passé (Wood et al 1989). Cela peut s'expliquer en partie par une intensité moindre de la synthèse d'acides gras (saturés) de novo à partir des glucides alimentaires. Quoi qu'il en soit, le degré d'insaturation des dépôts gras est fortement affecté par la nature du régime alimentaire, en l'occurrence par la présence d'acides gras polyinsaturés (acide linoléique), qui sont fixés directement dans les dépôts. Cet accroissement du taux d'insaturation des graisses, s'il correspond aux exigences du diététicien, constitue par contre un défaut (lard mou) aux yeux du technologue chargé de la mise en oeuvre des procédés de transformation, en particulier pour la charcuterie sèche. Pour satisfaire les contraintes technologiques, il convient ainsi de ne pas dépasser une certaine teneur en acides gras insaturés (acide linoléique) dans l'aliment, cette limite étant atteinte d'autant plus facilement que les porcs sont plus maigres. D'après les résultats de Mourot et al (1991), la teneur maximale recommandée en acide linoléique (C $18: 2$ ) dans l'aliment $(1,2$ à $1,5 \mathrm{~g} / \mathrm{kg})$ se situerait légèrement en dessous de la dose correspondant à la limite 
supérieure de $15 \%$ de $\mathrm{C} 18: 2$ dans les acides gras totaux du gras (bardière), à partir de laquelle on peut rencontrer des problèmes de transformation et de conservation. Les études à venir dans ce secteur devraient fournir des éléments permettant de concilier les impératifs pour l'instant opposés de la transformation et de la consommation.

\section{2 / Nécessité d'un compromis entre les impératifs de production d'une viande maigre et les exigences de qualité}

\section{a / Sélection sur la croissance musculaire et qualité de la viande}

Force est de constater, comme l'ont montré Ollivier et al (1991), que les efforts de la sélection en faveur du développement musculaire et d'une faible adiposité ont entraîné une certaine tendance à une détérioration de la qualité de la viande (tissus maigres) : diminution du $\mathrm{pH}$ ultime, du pouvoir de rétention d'eau et de la couleur. Cette tendance justifie l'intégration des critères de qualité des viandes dans les programmes de sélection, et on peut s'attendre à ce que le progrès génétique sur la vitesse de croissance et l'efficacité alimentaire soit quelque peu ralenti par la nécessité de freiner la lente dégradation des qualités technologiques et organoleptiques de la viande. Si la réduction du gras externe et intermusculaire demeure un objectif important pour les généticiens, une attention particulière devra être accordée au gras intramusculaire qui est, parmi les tissus adipeux, celui qui se développe le plus tardivement, et constitue un vecteur essentiel pour la tendreté et la flaveur des viandes. Selon Edwards et al (1992), des différences génétiques existent dans la répartition du gras entre les dépôts sous-cutanés et intramusculaires (plus élevés dans certaines races comme le Duroc et le Hampshire) ; de plus, il semble qu'un niveau minimum de gras intramusculaire soit nécessaire pour le maintien d'une bonne qualité organoleptique. En d'autres termes, cela pose le problème de la limite acceptable pour la diminution de l'état d'adiposité des carcasses (en particulier au niveau du gras intramusculaire), à la suite d'une sélection intense sur la croissance musculaire.

En dehors de la sélection, de nouvelles possibilités existent, qui permettent de préserver le potentiel de croissance musculaire (utilisation des porcs mâles entiers) ou de le stimuler (somatotropine porcine ou pST, $\beta$-agonistes), mais qui peuvent aussi avoir une incidence sur la qualité des produits.

\section{b / Maintien du potentiel de croissance musculaire par la suppression de la castration du porc mâle}

La suppression de la castration du porc mâle, en favorisant la croissance musculaire par rapport au mâle castré, constitue un moyen efficace pour améliorer la qualité des carcasses (teneur en muscle) et l'efficacité alimentaire (de l'ordre de $10 \%$ ), mais sa mise en oeuvre se heurte à des difficultés liées à l'apparition d'odeurs désagréables d'origine sexuelle (androsténone, scatol) dans les viandes de certains verrats (Bonneau 1988, Bonneau et al 1991, 1992a,b) : dans les conditions de la production du porc en France, environ $30 \%$ des verrats présentent une teneur en androsténone dans le gras supérieure à la valeur seuil de $0,5 \mathrm{ppm}$ pour l'apparition de défauts d'odeurs prononcés. Les possibilités de production sans risque de viande de porc mâle entier, pour l'instant limités à certains pays (Grande-Bretagne, Irlande, Pays-Bas, Danemark), sont fonction du type génétique (animaux sexuellement tardifs) et du poids à l'abattage (à un stade relativement léger). Des recherches complémentaires (détection des animaux à risque, sélection contre l'androsténone, immuno-castration) sont nécessaires avant de déboucher sur une faisabilité technique et économique de ce mode de production. Bien entendu, l'utilisation des porcs mâles entiers à la place des mâles castrés pour la production de viande se traduit par des changements importants dans la conduite alimentaire : besoins en acides aminés fortement accrus par rapport à l'énergie, possibilité d'alimentation à volonté.

\section{c / Stimulation du développement muscu- laire par les facteurs de croissance}

Les applications récentes des biotechnologies ont permis, par ailleurs, d'envisager le recours à des facteurs de croissance pour obtenir un accroissement supplémentaire du potentiel de production de viande maigre. Il en est ainsi de l'emploi de l'hormone de croissance ou somatotropine porcine de type recombinant (pST), dont l'efficacité sur la croissance du porc a fait l'objet, au cours des dernières années, d'un volume considérable de travaux (Verstegen et Van der Hel 1989, Bonneau 1990, 1992). L'administration de pST exogène exerce une stimulation spectaculaire de la croissance musculaire, accompagnée d'un dépôt fortement réduit des lipides dans l'organisme. L'accroissement du gain pondéral, associé à un dépôt plus important de protéines (et d'eau), a pour conséquence une nette diminution de son contenu et coût énergétique, et un abaissement correspondant de l'indice de consommation. Sous l'action de la pST, selon Noblet et al (1992), le rendement d'utilisation des protéines alimentaires pour la formation des dépôts corporels est augmenté. De plus, l'effet de la pST sur le gain de protéines et de tissus maigres est proportionnellement plus important chez les porcs de type gras que chez les animaux de type maigre. Mais, la rétention de protéines est de loin la plus élevée dans les génotypes les plus maigres, qui exigent également les apports de protéines et d'acides aminés les plus élevés, exprimés par jour ou relativement à l'énergie, ou en pourcentage de l'aliment. En ce qui concerne la qualité de la viande, les études réalisées (Bonneau 1990) ne semblent pas faire apparaître un effet particulier de la pST. Cependant, dans certaines

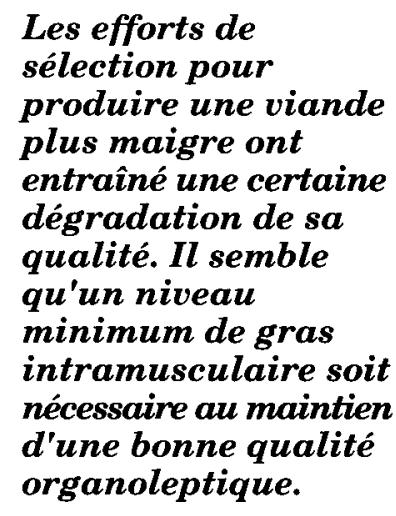


conditions (Mourot et al 1992b) on peut observer des modifications des caractéristiques du muscle (diminution de la teneur en gras intramusculaire) et des graisses de dépôt (augmentation du taux d'acides gras polyinsaturés). Cela signifie qu'il convient d'être prudent dans la fixation du seuil acceptable pour l'abaissement de l'état d'adiposité des carcasses de porc en relation avec la stimulation de la croissance musculaire. Comme la pST, les $\beta$-agonistes sont connus pour favoriser, chez le porc, la répartition de l'énergie fixée dans les tissus en faveur des protéines et au détriment des lipides (Hanrahan 1987, Williams 1987). Toutefois, cette stimulation de la croissance musculaire, moins importante qu'avec la pST, s'accompagne d'une accumulation de résidus dans les tissus, qui affecte la qualité hygiénique (ou valeur santé) de la viande (Vanbelle 1991).

\section{d / Alimentation et qualité des tissus maigres}

Alors que la qualité des tissus maigres est principalement déterminée par les facteurs génétiques (Monin, 1988), il existe par contre très peu d'indication sur les effets éventuels de l'alimentation dont la contribution, à ce niveau, est considérée comme mineure. Quoi qu'il en soit, quelques observations récentes ont permis de faire apparaître une influence de certains facteurs nutritionnels sur les propriétés physico-chimiques du tissu musculaire post-mortem et la qualité de la viande.

Parmi les acides aminés indispensables, l'apport supplémentaire de lysine, lorsqu'elle est limitante, n'a pas d'effet sur le type de fibres musculaires, mais tend à augmenter leur diamètre dans certains muscles, en particulier pour les fibres $\alpha \mathrm{R}$ (Whipple et al 1992). Dans la même étude, Goodband et al (1990) rapportaient une augmentation de l'aire transversale du muscle long dorsal après supplémentation en lysine, associée à une réduction de la jutosité et de la tendreté, ainsi qu'à une augmentation de la teneur en eau et en protéines au détriment des lipides.

De la même façon, à la suite d'une carence du régime en tryptophane (Henry et al 1992b), associée à une diminution de la synthèse de sérotonine dans l'hypothalamus, nous avons pu observer, par rapport à un régime témoin équilibré, une augmentation du $\mathrm{pH}$ musculaire, $45 \mathrm{~min}$ et $24 \mathrm{~h}$ post-mortem, mais seulement chez les porcs femelles, qui sont plus sensibles que les mâles castrés à un dysfonctionnement du système sérotoninergique. Par ailleurs, selon Adeola et Ball (1992), une surcharge en tryptophane alimentaire chez le porc en croissance - finition a pour effet de réduire la sévérité de l'état exsudatif (PSE) des viandes, en relation avec une diminution de l'état de stress des animaux. Cela semble ainsi expliquer (Henry et Sève 1993) que le pH ultime des muscles (jambon, longe) chez des porcs recevant des taux variables de tryptophane dans l'aliment est légèrement plus faible au taux optimum pour la croissance qu'à un taux soit déficient soit légèrement en excès par rapport au besoin
Parmi les vitamines, il a été montré (Mourot et al 1992a,c) qu'une supplémentation du régime en acide ascorbique ou vitamine $\mathrm{C}$, à la dose de $250 \mathrm{mg} / \mathrm{kg}$, entraîne une augmentation du $\mathrm{pH}$ ultime ( $24 \mathrm{~h}$ post-mortem) de la viande et une diminution de l'indice de couleur (viande plus sombre), en même temps qu'une amélioration $d u$ rendement technologique $d u$ jambon. La diminution du taux de cortisol circulant semble être une indication d'un état de stress moins important chez les animaux traités à la vitamine $\mathrm{C}$.

De nouvelles recherches sont nécessaires pour préciser les effets d'interactions possibles entre les facteurs nutritionnels (équilibre en acides aminés en relation avec les neurotransmetteurs, cofacteurs vitaminiques du métabolisme) et l'état physiologique de l'animal, notamment selon le statut génétique ou sexuel, et leur incidence sur les caractéristiques physico-chimiques du muscle et la qualité de la viande.

\section{e / Alimentation et conformation des carcasses}

Un point important concerne les possibilités de manipulation, par l'alimentation, de la conformation des carcasses, par les modifications qui s'ensuivent au niveau de la distribution anatomique des tissus et morceaux de découpe dans les différents compartiments corporels, ce qui n'est pas sans conséquence sur leur valorisation au plan commercial. Il est maintenant bien établi qu'une amélioration quantitative (taux de protéines) et qualitative (équilibre en acides aminés) de l'apport azoté agit non seulement favorablement et d'une manière globale sur le rapport muscle / gras dans les carcasses, mais en même temps elle contribue à modifier la conformation de ces dernières, dans le sens d'une stimulation du développement des régions les plus précoces (jambon, poitrine) par rapport au développement en longueur (longe), ce qui aboutit à des carcasses plus courtes pour un même poids à l'abattage. Il en est ainsi à la suite d'une élévation du niveau de l'acide aminé limitant du régime pendant tout l'engraissement et en alimentation à volonté, qu'il s'agisse de la lysine (Henry et al 1992a) ou du tryptophane (Henry et al 1992b, tableau 3). Si l'on confronte ces résultats à des données antérieures (Henry et al 1971), il semblerait que l'effet spécifique de l'apport azoté sur les régions corporelles, selon leur allométrie de croissance, serait lui-même en relation avec le statut génétique de l'animal : la sélection sur la croissance musculaire, en produisant des animaux à maturité de développement tissulaire plus tardive, permettrait de prolonger pendant l'engraissement l'influence favorable des acides aminés sur la croissance des régions à maturité de développement précoce. A l'opposé, nous avons pu montrer (Bourdon et Henry 1991, tableau 3) qu'une restriction de l'apport énergétique chez le porc en finition jusqu'à un poids à l'abattage constant de $100 \mathrm{~kg}$ favorise l'allongement des carcasses (développement de la longe), lequel est encore accru en présence d'un apport sup- 
Tableau 3. Influence du niveau des apports alimentaires d'acides aminés et d'énergie sur la longueur de la carcasse du porc à l'abattage (longueur totale entre l'atlas et le bord antérieur de la symphyse pubienne).

\begin{tabular}{|c|c|c|c|c|c|c|c|c|}
\hline & \multicolumn{4}{|c|}{ Acide aminé $(\%)$} & \multicolumn{4}{|c|}{ Energie $^{c}$} \\
\hline & \multicolumn{2}{|c|}{ Lysine $^{\mathrm{a}}$} & \multicolumn{2}{|c|}{ Tryptophane $^{b}$} & \multicolumn{2}{|c|}{ Femelles } & \multicolumn{2}{|c|}{ Mâles castrés } \\
\hline & 0,55 & 0,65 & 0,09 & 0,13 & 90 & 100 & 80 & 100 \\
\hline Longueur carcasse $(\mathrm{cm})$ & 103,8 & 102,6 & 100,0 & 98,4 & 103,2 & 100,4 & 101,8 & 99,4 \\
\hline
\end{tabular}

${ }^{2}$ Henry et al (1992a) : 42 - $101 \mathrm{~kg}$ de poids vif (PV); poids de la carcasse chaude avec tête : $83,9 \mathrm{~kg}$; alimentation à volonté.

${ }^{\mathrm{b}}$ Henry et al (1992b): 44 - $99 \mathrm{~kg}$ PV; poids de la carcasse chaude avec tête : $83,2 \mathrm{~kg}$.

'Bourbon et Henry (1991) : 40 - 100 kg PV, poids de la carcasse chaude 82,5 kg; niveau 100 proche du niveau à volonté.

plémentaire de lysine, lorsque cet acide aminé est limitant. Notons par ailleurs, selon Lefaucheur et al (1991), que l'exposition du porc au froid, par rapport à une température se rapprochant de la thermoneutralité et dans les conditions d'alimentation à volonté, ne modifie pas significativement la vitesse de croissance, ni les teneurs en muscle et en gras des carcasses, mais elle provoque un changement de leur conformation (plus courtes et plus compactes), ainsi qu'une modification de la répartition des dépôts gras dans l'organisme (développement accru des dépôts externes au détriment des dépôts internes (y compris au niveau du jambon), en relation avec les mécanismes de thermorégulation. En outre, d'après Sève et al (1985), la composition corporelle à l'abattage, et probablement la conformation des carcasses, peuvent être affectées d'une manière particulière par le niveau d'alimentation dès le jeune âge (après sevrage). En définitive, les conditions d'une meilleure maîtrise de la conformation des carcasses, selon le poids commercial à l'abattage, mériteraient d'être étudiées sous l'angle nouveau des interrelations type génétique - allométrie de développement tissulaire - stade de croissance - niveaux respectifs de nutriments énergétiques et azotés - conditions de milieu.

\section{$f$ / Sélection sur la croissance musculaire et reproduction}

Sur un plan plus particulier, on peut s'interroger sur les conséquences à terme d'une sélection intense pour la croissance musculaire et contre le dépôt gras sur la reproduction du porc (état des réserves lipidiques corporelles chez la truie) et sa longévité (intégrité des aplombs, liée à la charge musculaire et à l'intensité du croît). Il apparaît d'ores et déjà que les truies issues des génotypes modernes disposent d'une quantité insuffisante de gras pour faire face à des dépenses énergétiques de lactation de plus en plus importantes au fur et à mesure de l'accroissement de la prolificité et de la productivité numérique (Reese et al 1984, Dourmad 1991, Etienne et al 1991). Ce risque d'amaigrissement excessif des truies peut avoir une incidence défavorable sur les performances de reproduction elles-mêmes. En dehors de l'intérêt de préserver une lignée maternelle capable de s'adapter sans risque à une carrière reproductive aussi intense que longue, cela justifie un approfondissement des mécanismes de mobilisation et de reconstitution des réserves corporelles chez la truie de type maigre.

\section{Conclusion}

L'alimentation du porc a subi de profonds changements au cours des dernières décennies, à la suite des progrès importants et continus réalisés par la sélection pour une croissance toujours plus forte de tissus maigres et un dépôt décroissant de gras. En raison de l'importance du progrès génétique réalisé en faveur de la croissance des tissus maigres, il a été nécessaire d'envisager une modélisation de la prévision des besoins nutritionnels (énergie, protéines et acides aminés, minéraux), dont les variations se traduisent notamment par des exigences moins marquées en énergie que par le passé et par un accroissement important des besoins en acides aminés relativement à l'apport énergétique. Grâce à cette démarche de modélisation, il est désormais possible de définir des stratégies d'alimentation appropriées (plan de rationnement alimentaire, choix d'un type d'aliment pour une phase de production déterminée), en fonction des conditions particulières de production et à l'aide de systèmes d'évaluation des aliments suffisamment discriminants (énergie nette, digestibilité iléale des acides aminés). En même temps, l'augmentation de certains intrants alimentaires (azote, phosphore) pour une production accrue de viande maigre implique une gestion raisonnée de leurs apports, de manière à prévenir des rejets excessifs dans l'environnement (eau, atmosphère).

Bien entendu, l'obtention des performances les meilleures pour la production de porc maigre, au coût d'alimentation le plus bas, ne constitue pas forcément un objectif ultime de portée générale. En réalité, les nouvelles approches en matière d'alimentation du porc, basées sur l'établissement de lois de réponse qui prennent en compte la diversité à la fois des types d'animaux (depuis les plus gras jusqu'aux plus maigres) et des conditions d'élevage et de milieu, pour répondre à des besoins différents, voire divergents, des collectivités, devraient permettre, dans chaque cas, de définir les conditions optimales de production d'un type de porc particulier.

Pour l'avenir, la tendance à une certaine dégradation de la qualité de la viande, notamment sous l'angle technologique et organoleptique, au fur et à mesure des progrès de la sélection sur la croissance musculaire, conduit à s'interroger sur la limite acceptable pour la réduction de l'état d'adiposité des carcasses, en particulier au niveau du gras intramusculaire. D'ores et déjà, la qualité de la viande est prise 
en compte dans les programmes de sélection, soit indirectement par une révision de la pondération des critères dans les index de sélection, soit directement par l'introduction dans ces derniers des critères de qualité. Les progrès attendus des travaux en amélioration génétique devraient permettre de mieux comprendre les antagonismes éventuels entre la quantité de muscle et sa qualité (viandes acides), notamment par l'estimation des corrélations génétiques entre les critères de production et ceux relatifs à la qualité de la viande. Ce problème d'équilibre entre les tissus musculaire et gras dans les dépôts corporels constitue un enjeu important pour l'évolution future de l'alimentation du porc maigre.

\section{Références bibliographiques}

Adeola O., Ball R.O., 1992. Hypothalamic neurotransmitter concentrations and meat quality in stressed pigs offered excess dietary tryptophan and tyrosine. J.Anim.Sci., 70, 1888-1894.

Aumaitre A., 1991. L'industrialisation de l'élevage porcin : quelles solutions pour le respect de l'environnement et le bien-être des animaux. Rassegna Suinicola Internationale, Reggio Emilia (Italie).

Black J.L., Campbell R.G., Williams I.H., James K.J., Davies G.T., 1986. Simulation of energy and amino acid utilisation in the pig. Research and Development in Agriculture, 3, 121-145.

Beers S., Jongbloed A.W., 1992. Phosphorus digestibility and requirements of pigs. 2nd Internat. Feed Production Conference, Piacenza, Facolta di Agraria (Italia).

Bonneau M., 1988. Intérêt et limites de la production de viandes de porc mâle entier. INRA Prod. Anim., 1, 133-140.

Bonneau M, 1990. Régulation de la croissance du porc par la somatotropine et les autres hormones de l'axe somatotrope : sécrétion, mécanismes d'action et effets sur les performances. Journées Rech.Porcine en France, 22, 51-67.

Bonneau M., 1992. Administration de GRF ou de somatotropine chez le porc et les volailles : Effets sur les performances, la qualité des viandes et la fonction de reproduction. INRA Prod.Anim., 5, 257 267.

Bonneau M., Le Denmat M., Vaudelet J.C., VelosoNunes J.R., 1991. Qualité organoleptique des viandes fraiches et du jambon de porcs mâles entiers ou castrés : relations avec les teneurs en androsténone ou en scatol des graisses. Journées Rech.Porcine en France, 23, 325-337.

Bonneau M., Le Denmat M., Vaudelet J.C., Veloso Nunes J.R., Mortensen A.B., Mortensen H.P., 1992a. Contributions of fat androstenone and skatole to boar taint: I. Sensory attributes of fat and pork meat. Livest.Prod.Sci., 32, 63-80.

Bonneau M., Le Denmat M., Vaudelet J.C., Veloso Nunes J.R., Mortensen A.B., Mortensen H.P., 1992 b. Contributions of fat androstenone and skatoleto boar taint : II. Eating quality of cooked hams. Livest.Prod.Sci., 32, 81-88.

Bourdon D., Henry Y., 1991. Réponse du porc en finition à la supplémentation du régime en lysine, en fonction du niveau de rationnement et selon le sexe. Journées Rech.Porcine en France, 23, 111-118.

Campbell R.G., 1988. Nutritional constraints to lean tissue accretion in farm animals. Nutr.Res.Rev., 1, 233-253.
C.V.B. 1990. Table about apparent ileal digestible amino acids in feedstuffs for pigs (In Dutch). Centraal Veevorbureau in Nederland, Lelystad, 19 pp.

Dagorn J., Badouard C., Legault C., 1992. GTT : A pig herd management system. 43rd EAAP Meeting, Satellite Symposium - Pig Management Information Systems, Madrid (Spain).

Desmoulin B., Bonneau M., 1979. Production de viandes de porcs mâles entiers ou castrés chez les types Piétrain ou Landrace Belge. Journées Rech.Porcine en France, 11, 113-120.

Dourmad J.Y., 1991. Effect of feeding level in the gilt during pregnancy on voluntary feed intake during lactation and changes in body composition during gestation and lactation. Livest. Prod. Sci., 27, 309-319.

Dourmad J.Y., Etienne M., Noblet J., 1991. Contribution à l'étude des besoins en acides aminés de la truie en lactation. Journées Rech.Porcine en France. 23, 61-68.

Dourmad J.Y., Guillou D., 1991. Maîtrise de la charge polluante des effluents des élevages porcins : influence du bâtiment, de l'alimentation et des performances. AFMVP - SIMAVIP, Paris, pp. 35-46.

Dourmad J.Y., Guillou D., Noblet J., 1992. Development of a calculation model for predicting the amount of $\mathrm{N}$ excreted by the pig : effect of feeding, physiological stage and performance. Livest. Prod. Sci., 31, 95-107.

Edwards S.A., Wood J.D., Moncrieff C.B., Porter S.J., 1992. Comparison of the Duroc and Large White as terminal sire breeds and their effect on pigmeat quality. Anim.Prod., 54, 289-297.

Etienne M., Dourmad J.Y., Barrios A., Noblet J., 1991. La reconstitution des réserves corporelles chez la truie multipare en gestation : influence des apports d'énergie. Journées Rech.Porcine en France, $23,75-84$

Eurolysine. 1989. Coefficients de digestibilité iléale apparente des acides aminés essentiels des matières premières pour l'alimentation du porc. Eurolysine, Paris.

FAO, 1990. World Meat Situation and Outlook. FAO, Rome.

Fuller M.F., 1991. Present knowledge of amino acid requirements for maintenance and production : nonruminants. In : Proc.6th Internat.Symp.Protein Metabolism and Nutrition (B.O.Eggum, S.Boisen, C.Börsting, A.Danfaer and T.Hvelplund, Ed.). Vol.1. Main reports, pp 116-126.EAAP Pub. No.59. Nat.Inst.Anim.Sci., Foulum, Denmark. 
Goodband R.D., Nielsen J.L., Hines R.H., Kropf D.H., Thaler R.C., Schricker B.R., Fitzner G.E., Lewis A.J., 1990. The effects of porcine somatotropin and dietary lysine on growth performance and carcass characteristics of finishing swine. J.Anim.Sci., 68, 3261-3276.

Guéguen L., Perez J.M., 1981. A re-evaluation of recommended dietary allowances of calcium and phosphorus for pigs. Proc. Nutr. Soc., 40, 273-278.

Hanrahan J.P., 1987. Beta-agonists and their effects on animal growth and carcass quality. Elsevier, London.

Henry Y., 1988. Signification de la protéine équilibrée pour le porc : intérêt et limites. INRA Prod. Anim. 1, 65-74.

Henry Y., 1991. Répercussions des techniques actuelles de production animale sur l'environnement. Acad. Vétérinaire de France, Paris.

Henry Y., Arnal M., Obled C., Rérat A., 1988. Protein and amino acid requirements of pigs. In : Protein Metabolism and Nutrition, EAAP Publ. ${ }^{\circ}$ 35, Wiss.Zeitsch. Univ. Rostock, N-Reihe, 1, S 9-18.

Henry Y., Colléaux Y., Sève B., 1992a. Effects of dietary level of lysine and of level and source of protein on feed intake, growth performance, and plasma amino acid pattern in the finishing pig. J.Anim.Sci., 70, 188-195.

Henry Y., Dourmad J.Y., 1992. Protein nutrition and $\mathrm{N}$ pollution in pigs. 2nd Internat. Feed Production Conference, Piacenza, Facolta di Agraria (Italia).

Henry Y., Rérat A., Tomassone R., 1971. Etude du besoin en lysine du porc en croissance - finition. Application de l'analyse multidimensionnelle. Ann.Zoot., 20, 521-550.

Henry Y., Sève B., 1991. Incidence de l'équilibre en acides aminés du régime sur l'appétit et la croissance du porc, selon le taux de protéines et leur nature : l'exemple du tryptophane. Journées Rech. Porcine, 23, 119-126.

Henry Y., Sève B., 1993. Prise en compte de l'excès alimentaire d'acides aminés neutres pour la correction de l'équilibre du tryptophane par rapport à la lysine chez le porc en croissance. Journées Rech.Porcine en France, 25, 247-253.

Henry Y., Sève B., Colléaux Y., Ganier P., Saligaut C., Jégo P., 1992b. Interactive effects of dietary levels of tryptophan and protein on voluntary feed intake and growth performance in pigs, in relation to plasma free amino acids and hypothalamic serotonin. J. Anim. Sci., 70, 1873-1887.

Henry Y., Vogt H., Zoiopoulos P.E., 1988b. Feed evaluation and nutritional requirements : Pigs and Poultry. In : Livestock Feed Resources and Feed Evaluation in Europe (F.de Boer and H.Bickel, Ed.). EAAP Pub. № 37, Chap. III.4, pp 299-354. Elsevier, Amsterdam.

INRA, 1989. L'alimentation des animaux monogastriques : porc, lapin, volailles. 2e édition. INRA, Paris, $282 \mathrm{pp}$.

Jongbloed A.W., 1987. Phosphorus in the feeding of pigs. Thesis, Rapport IVVO No 179 , Lelystad, The Netherlands.
Jongbloed A.W., Everts H., Kemme P.A., 1991. Phosphorus availability and requirements in pigs. In : Recent Advances in Animal Nutrition (W.Haresign and D.J.A.Cole, Ed.) 65-80. Butterworths, London.

Jongbloed A.W., Lenis N.P., 1992. Alterations of nutrition as a means to reduce environmental pollution by pigs. Livest.Prod.Sci., 31, 75-94.

Karege C., 1991. Influence de l'âge et du sexe sur l'utilisation de l'énergie et la composition corporelle chez le porc en croissance. Thèse, Univ. Montpellier II, Sciences et Techniques du Languedoc.

Laplace J.P., Darcy-Vrillon B., Picard M., 1985. Evaluation de la disponibilité des acides aminés : choix raisonné d'une méthode. Journées Rech. Porcine en France, 17, 353-370.

Leclercq B., Legault C., 1991. Evolution prévisible des filières et de leurs problèmes chez les monogastriques. Séminaire sur l'élevage, INRA, Theix.

Le Dividich J., Rinaldo D., 1989. Effets de l'environnement thermique sur les performances du porc en croissance. Journées Rech.Porcine en France, $21: 219-230$.

Lefaucheur L., Le Dividich J., Mourot J., Monin G., Ecolan P., Krauss D., 1991. Influence of environmental temperature on growth, muscle and adipose tissue metabolism, and meat quality in swine. J.Anim.Sci., 69, 2844-2854.

Lenis N.P., 1989. Lower nitrogen excretion in pig husbandry by feeding : current and future possibilities. Neth.J.Agric.Sci., 37, 61-70.

Mariscal-Landin G., 1992. Facteurs de variation de l'utilisation digestive des acides aminés chez le porc. Thèse, Univ. Rennes I, U.F.R. Sciences de la Vie et de l'Environnement.

Mariscal-Landin G., Wiesemüller W., Meier H., Sève B., Henry Y., 1991. Precaecal protein digestibility in feedstuffs of animal origin. In : Proc. 6th Internat. Symp. Protein Metabolism and Nutrition (B.O.Eggum, S.Boisen, C.Börsting, A.Danfaer and T. Hvelplund, Ed.). Vol.2, pp 39-41. EAAP Pubb. $\mathrm{N}^{\circ} 59$. Nat.Inst.Anim.Sci., Foulum, Denmark.

Monin G., 1988. Evolution post-mortem du tissu musculaire et conséquences sur les qualités de la viande de porc. Journées Rech.Porcine en France, 20, 201-213.

Moughan P.J., 1989. Simulation of the daily partitioning of lysine in the $50 \mathrm{~kg}$ liveweight pig - $\mathrm{A}$ factorial approach to estimating amino acid requirements for growth and maintenance. Research and development in Agriculture, 6, 7-14.

Moughan P.J., Smith W.C., Pearson W.C., 1987. Desciption and validation of a model simulating growth in the pig $(20-90 \mathrm{~kg}$ liveweight). New Zealand J. Agric. Res., 30, 481-489.

Mourot J., Aumaître A., Wallet P., 1992a. Effect of a dietary supplement of vitamin $\mathrm{C}$ on growth and pig meat quality. In : C.Wenk, R.Fenster and R.Volker (Ed.) Ascorbic Acid in Domestic Animals. pp 176185. Hoffmann - La Roche, Basel.

Mourot J., Bonneau M., Charlotin P., Lefaucheur L., 1992b. Effects of exogenous porcine somatotropin (pST) administration on pork meat quality. Meat Sci., 31, 219-227. 
Mourot J., Chauvel J., Le Denmat M., Mounier A., Peiniau P., 1991. Journées Rech.Porcine en France, 23, 357-364.

Mourot J., Peiniau P., Aumaitre A., Chevillon P., 1992c. Effet de l'apport de vitamine C sur les performances de croissance et la qualité de la viande chez des porcs Large White et croisés Large WhitePiétrain. Journées Rech.Porcine en France, 24, 5564.

Noblet J., Dourmad J.Y., Etienne M., 1990. Energy utilization in pregnant and lactating sows modelling of energy requirements. J. Anim. Sci., 68, $562-572$.

Noblet J., Dubois S., Herpin P., Sève B., 1992. Influence de l'utilisation de la somatotropine porcine sur l'utilisation de l'énergie et des protéines chez le porc. Conséquences sur les besoins nutritionnels. Journées Rech.Porcine en France, 24, 237-248.

Noblet J., Etienne M., Dourmad J.Y., 1988. Besoins énergétiques de la truie allaitante : détermination par la méthode factorielle. INRA Prod.Anim., 1, 355358.

Noblet, J., Fortune H., Dubois S., Henry Y., 1989a. Nouvelles bases d'estimation des teneurs en énergie digestible, métabolisable et nette des aliments pour le porc. INRA, Paris, $106 \mathrm{pp}$.

Noblet J., Fortune H., Dupire C., Dubois S., 1990. Valeur nutritionnelle de treize matières premières pour le porc en croissance. 1 . Teneurs en énergie digestible, métabolisable et nette. Conséquences du choix du système énergétique. Journées Rech.Porcine en France, 22, 175-184.

Noblet J., Henry Y. 1991, Energy evaluation systems for pig diets. In : Manipulating Pig Production III (E.S.Batterham, Ed.).pp 87-110. Australasian Pig Science Association, Attwood, Victoria (Australia).

Noblet J., Henry Y., Dubois S. 1987. Effect of protein and lysine levels in the diet on body gain composition and energy utilization in growing pigs. J.Anim.Sci., 65, 717-726.

Noblet J., Karege C., Dubois S., 1989b. Influence of sex and genotype on energy utilization in growing pigs. In : Energy Metabolism of Farm Animals (Y.van der Honing and W.H.Close, Ed.). pp 57-60. EAAP Pub. $\mathrm{N}^{\circ}$ 43. Pudoc, Wageningen (The Netherlands).

Noblet J., Karege C., Dubois S., 1991. Influence of growth potential on energy requirements for maintenance in growing pigs. In : Energy Metabolism of Farm Animals (C.Wenk, Ed.). pp 107110. EAAP Pub.N ${ }^{\circ} 58$, ETH-Zürich (Switzerland).

Ollivier L., Lagant H., Gruand J., Molénat M., 1991. Progrès génétique des porcs Large White et Landrace Français de 1977 à 1987. Journées Rech.Porcine en France, 23, 389-394.

Pessara H., Oldenburg J., 1992. Eiweiszreduzierung im Schweinemastfutter : Läszt sicht die Ammoniakemission senken? DGS (Deutsche Geflügelwirtschaft und Schweineproduction).Verlag Eugen Ulmer, Stuttgart (Germany), 5, 144-146.

Pointillart A., Colin C., Lacroix C., Radisson J., 1993. Réduction, chez le porc en croissance, de la supplémentation en Phosphore minéral par l'utilisation de céréales à activité phytasique élevée. Journées Rech.Porcine en France, 25, $233-238$.
Reese D.E., Peo E.R., Lewis A.J., 1984. Relationship of lactation energy intake and occurrence of postweaning estrus to body and backfat composition in sows. J.Anim.Sci., 58, 1236-1244.

Rérat A., 1991. Carbohydrate interactions on protein and amino acid digestibility and absorption and metabolic consequences in the pig. In : Proc.6th Internat.Symp.Protein Metabolism and Nutrition (B.O.Eggum, S.Boisen, C.Börsting, A.Danfaer and T.Hvelplund, Ed.). Vol.1. Main reports, pp 37-53. EAAP Pub.No 59. Nat.Inst.Anim.Sci., Foulum, Denmark.

Rinaldo D., Le Dividich J., 1991. Influence de la température ambiante sur les performances de croissance du porc. INRA Prod.Anim., 4, 57-65.

RPAN, 1989. Nutrition Guide. Formulation des aliments en acides aminés digestibles. RhônePoulenc Animal Nutrition, Antony, 35pp.

Schiemann R., Nehring K., Hoffmann L., Jentsch W., Chudy A., 1972. Energetische Futterbewertung und Energienormen. VEB Deutscher Landwirtschaftsverlag, Berlin, 344 pp.

Sève B., Ballèvre O., 1991. Approches métaboliques du besoin en acides aminés chez le porc en croissance. Journées Rech. Porcine en France, 23 : 91-110.

Sève B., Perez J.M., Desmoulin B., 1985. Effet à long terme du niveau d'alimentation du porcelet entre 10 et $20 \mathrm{~kg}$ de poids vif sur les performances et la composition corporelle à l'abattage. Interaction avec le rationnement en période de croissance - finition. Journées Rech.Porcine en France, 17, 419-431.

Tamminga S., Verstegen M.W.A., 1991. Protein nutrition and animal production : consequences for environments and some possible recommendations. In : Proc 6th Internat. Symp. Protein Metabolism and nutrition (B.O.Eggum, S.Boisen C.Börsting, A.Danfaer and T.Hvelplund, Ed.). Vol.1.Main reports, pp 23-36. EAAP Publication No 59. Nat.Inst.Anim.Sci., Foulum, Denmark.

Vanbelle M., 1991. Avantages et inconvénients des ß-agonistes en production animale. Bull.Acad. Vét. de France, 64 (supp. au n ${ }^{\circ}$ 4), 55-74.

Verstegen M.W.A., van der Hel W., 1989. Effect of porcine somatotropin on nitrogen gain and energy metabolism in fattening pigs. In : Nutrition and Digestive Physiology in Monogastric Farm Animals (E.J. van Weerden and J.Huisman, Ed.), pp 57-74. Pudoc, Wageningen.

Whipple G., Hunt M.C., Klemm R.D., Kropf D.H., Goodband R.D., Schricker B.R., 1992. Effects of porcine somatotropin and supplemental lysine on porcine muscle histochemistry. J.Muscle Foods, 3, 217-227.

Whittemore C.T., 1983. Development of recommended energy and protein allowances for growing pigs. Agricultural Systems, 11, 159-186.

Williams P.E.V., 1987. The use of $\beta$-agonists as a means of altering body composition in livestock species. Nutr.Abstr.Rev.(Series B), 57, 453-464.

Wood J.D., Enser M., Whittington F.M., Moncrieff C.B., Kempster A.J., 1989. Backfat composition in pigs : differences between fat thickness groups and sexes. Livest. Prod. Sci., 22, 351-362. 


\section{Summary}

Pig feeding for lean meat production : recent developments and prospects.

During the last decades, pig production has gained important and continuous progress from selection for constantly increasing lean tissue gain and decreasing fat deposition, in order to meet the increasing demand of market and consumer. The present report is intended to examine the changes that have been introduced in pig feeding to bring the necessary adaptations for optimizing growth performance, by considering the recent development and the trends for the future, in relation to the predictable shift in production performance and technological innovations.

The unceasingly changing contribution of animal related factors has made it necessary to consider prediction modelling of nutritional requirements (energy, protein and amino acids), with a general trend to lower energy needs than in the past and higher amino acid requirements relative to energy.

This modelling approach allows to implement new feeding strategies (feeding scale, type of feed for a given phase of production) that are adapted to lean meat production, according to specific production conditions and with sufficiently discriminating feed evaluation systems (net energy, ileal amino acid digestibility). In addition, the steady increase in some dietary inputs (nitrogen, phosphorus) for expanded lean meat production implies a sound management of nutrient supply, in order to prevent excessive loss to the environment (water, atmosphere).

The observed trend to some degradation of meat quality with intense selection for muscular growth, particularly with regard to technological and organoleptic characteristics, necessitates to take into account these constraints in feeding, whether one considers fat deposition or lean tissue gain (extent of intramuscular fat). Finally, after examining the effects of feeding on carcass conforma. tion, we have considered the incidence of excessive leanness in sows on reproduction performance, in relation to mobilization and restauration of body lipid reserves. This problem of optimum balance between lean and fat is an important chal. lenge for future evolution of feeding lean pigs. From practical standpoint, the new nutritional approaches based on establishing dose - response relationships that integrate the diversity of available genotypes (from the fattest to the leannest), along with production and environmental conditions, should contribute, in each case, to fix the optimum conditions for producing a given type of pig.

HENRY Y., 1993. Alimentation du porc pour la production de viande maigre : évolutions récentes et perspectives. INRA Prod. Anim., 6 (1), 31 - 45. 